\title{
RNA interference-mediated hTERT inhibition enhances TRAIL-induced apoptosis in resistant hepatocellular carcinoma cells
}

\author{
RU-GANG ZHANG* , JING-JING ZHAO* , LIU-QIN YANG, SHI-MING YANG, \\ RONG-QUAN WANG, WEN-SHENG CHEN, GUI-YONG PENG and DIAN-CHUN FANG
}

Department of Gastroenterology, Southwest Hospital, Third Military Medical University, Chongqing 400038, P.R. China

Received November 5, 2009; Accepted December 30, 2009

DOI: $10.3892 /$ or_00000727

\begin{abstract}
TRAIL has been reported to induce apoptosis in a variety of tumor cell types including hepato-cellular carcinoma (HCC) cell lines. However, considerable numbers of HCC cells, especially some highly malignant tumors, show resistance to TRAIL-induced apoptosis. The molecular mechanisms that regulate sensitivity versus resistance of tumor cells to TRAIL-induced apoptosis remain poorly defined. It has been shown that human telomerase catalytic subunit (hTERT) is overexpressed in human HCCs. In this study, we investigated the effects and the mechanisms of hTERT RNAi on the TRAIL-induced apoptosis of HCC cells that exhibit resistance to TRAIL. Our results indicate that hTERT RNAi sensitizes TRAIL-resistant HCC cells to TRAIL-induced apoptosis. hTERT RNAi-mediated sensitization to TRAIL-induced apoptosis is accompanied upregulation of procaspases- 8 and -9 , inhibition of telomerase activity and loss of telomere length. Our results suggest that hTERT RNAi overcame the resistance of the HCC cells against TRAIL, at least in part, via the mitochondrial type II apoptosis pathway and telomerase-dependent pathway.
\end{abstract}

\section{Introduction}

The tumor necrosis factor-related apoptosis-inducing ligand (TRAIL) is regarded as a potential anticancer agent (1). However, considerable numbers of cancer cells, especially some highly malignant tumors, are resistant to apoptosis induced by TRAIL, and some cancer cells that were originally sensitive to TRAIL-induced apoptosis can become resistant after repeated exposure (acquired resistance). Understanding

Correspondence to: Dr Dian-chun Fang, Department of Gastroenterology, Southwest Hospital, Third Military Medical University, Chongqing 400038, P.R. China

E-mail: fangdianchun@hotmail.com

${ }^{*}$ Contributed equally

Key words: telomerase, telomere, human telomerase reverse transcriptase, procaspase- 8 and -9 , hepatocellular carcinomas the mechanisms underlying such resistance and developing strategies to overcome it are important for the successful use of TRAIL for cancer therapy (2).

Human telomerase is a ribonucleoprotein composed of human telomerase RNA component (hTR) (3), human telomerase catalytic subunit (hTERT) (4) and TEP1, a telomeraseassociated protein (5). There is a strong correlation between the presence of hTERT mRNA and telomerase activity and it is recognized that hTERT is the rate-limiting determinant of the enzymatic activity of human telomerase $(4,6,7)$. The expression of hTERT mRNA is detected at high levels in tumor tissues and tumor-derived cell lines but not in normal adjacent tissues or primary cells (8-12). Owing to this differential expression pattern in normal and tumors cells, hTERT has been proposed as a promising target for anticancer therapies.

Hepatocellular carcinomas (HCCs) are drug-resistant tumors that frequently possess high telomerase activity. Reactivation of telomerase activity is a characteristic molecular mechanism in hepatocarcinogenesis and it has been shown that hTERT is overexpressed in $80-100 \%$ of human HCCs (12-14). The effect of hTERT RNAi on the induction of apoptosis in TRAIL-resistant HCC cell lines is poorly understood. It was therefore the aim of this study to investigate the effect and the mechanisms of hTERT RNAi on the TRAILinduced apoptosis of HCC cells. We firstly constructed eukaryotic expression plasmid of hTERT RNAi, then transfected it into the human HCC cell lines Huh7 and Hep3B, examined cellular apoptosis, apoptosis-associated protein expression, telomerase activity and telomere length in transfected HCC cells. Our data show that hTERT RNAi increase procaspase- 8 and -9 expression, inhibit telomerase activity and shorten telomere length, which accounts for the sensitization to TRAIL-induced apoptosis.

\section{Materials and methods}

Construction of eukaryotic expression vector of hTERT RNAi. We introduced hTERT sequence from nucleotides 3114-3134, followed by $9 \mathrm{bp}$ to form a loop and the corresponding antisense hTERT nucleotides, followed by six uridines into pSilencer 3.1-H1 neo vector (Ambion, USA). The sequences used for the hairpin were: forward, 5'-GATCCGTTT CATCAGCAAGTTTGGATTCAAGAGATCCAAACTTG 
CTGATGAAATTTTTTGGAAA-3'; and reverse, 5'-AGC TTTTCCAAAAAATTTCATCAGCAAGTTTGGATCTC TTGAATCCAAACTTGCTGATGAAACG-3', where the underlined letters represent hTERT sequences (15). The small hairpin hTERT (shTERT) sequences were annealed, then directly cloned in order to form eukaryotic expression vector of hTERT RNAi, pSilencer 3.1-H1 neo-shTERT, according to the manufacturer's protocol from Ambion.

Identification of recombinant plasmids. Presence of the insert sequence in the recombinant plasmid after DH5 $\alpha$ transformation (12) was verified by: 1) PCR amplification with universal primers of M13F(-40) (Sangon, Shanghai, China), 5'-GTT TTC CCA GTC ACG AC-3' and $3.0 \mathrm{rev}$, 5'-GAG $^{-}$ TTA GCT CAC TCA TTA GGC-3'. If there was the insert sequence of hTERT RNAi, size of amplification product would be $327 \mathrm{bp}$, otherwise $263 \mathrm{bp} ; 2$ ) assay of restriction enzymes, which produced fragments of 4288 bp for BamHI (Promega, USA), and 4224 bp and 64 bp for BamHI and HindIII (Promega); 3) DNA sequencing to the recombinant plasmid in Sangon. The insert sequence was correct.

Cell culture and transfection. The human HCC cell lines Huh7 and Hep3B were obtained from American Type Culture Collection. Cells were cultured in Dulbecco's modified Eagle's medium (DMEM, Hyclone, USA) supplemented with $10 \% \mathrm{FCS}, 100 \mathrm{U} / \mathrm{ml}$ penicillin, and $100 \mathrm{~g} / \mathrm{ml}$ streptomycin, and were maintained in a humidified atmosphere of $95 \%$ air and $5 \% \mathrm{CO}_{2}$ at $37^{\circ} \mathrm{C}$. Huh7 and Hep3B cells were stably transfected using transfection reagent DOGS (Ambion) with pSilencer 3.1-H1 neo-shTERT or pSilencer 3.1-H1 neo negative control plasmids (Ambion). The former was the transfected group and the latter the control group.

Identification of interference sequences. As the recombinant plasmid, we also applied the universal primers of M13(-40) and $3.0 \mathrm{rev}$ to confirm the interference sequences of transfection and control cells. The size of amplification product would be $327 \mathrm{bp}$ in transfected cells, $324 \mathrm{bp}$ in control cells.

Reverse transcription-PCR (RT-PCR). RT-PCR was performed to detect mRNA expression of hTERT and glyceraldehyde phosphate dehydrogenase (GAPDH) as described (16). hTERT was amplified using the primer pair 5'-CGG AAG AGT GTC TGG AGC AA-3' (LT5) and 5'-CTC AGA CAC CAT GGG GAA GGT GA-3' (LT6) for 35 cycles $\left(94^{\circ} \mathrm{C}\right.$ for $45 \mathrm{sec}, 60^{\circ} \mathrm{C}$ for $45 \mathrm{sec}$ and $72^{\circ} \mathrm{C}$ for $\left.90 \mathrm{sec}\right)$. GAPDH was amplified using primers 5'-CTC AGA CAC CAT GGG GAA GGT GA-3' (K136) and 5'-ATG ATC TTG AGG CTG TTG TCA TA-3' (K137) for 20 cycles $\left(94^{\circ} \mathrm{C}\right.$ for $45 \mathrm{sec}, 60^{\circ} \mathrm{C}$ for $45 \mathrm{sec}$ and $72^{\circ} \mathrm{C}$ for $90 \mathrm{sec}$ ). Amplification products were then resolved on $12 \%$ nondenaturing polyacrylamide gel. hTERT interference rate $(\%)$ was $\left[1-\left(\mathrm{A}_{\text {sample }} \times \mathrm{A}_{0 \text { control }}\right) /\left(\mathrm{A}_{0 \text { sample }} \times \mathrm{A}_{\text {control }}\right)\right.$ $\mathrm{x} 100 \%]$. $\mathrm{A}_{\text {sample }}$ was the hTERT densitometric value of the transfection or control cells. $A_{0 \text { control }}$ was the GAPDH densitometric value of untransfection cells. $A_{0 \text { sample }}$ was the GAPDH densitometric value of untransfection cells. $A_{\text {control }}$ was the hTERT densitometric value of untransfection cells. Results were repeated twice.
Apoptosis assays. Cellular apoptosis was evaluated with Annexin V-FITC kit (Senzen, China) according to the manufacturer's protocols. Briefly, cells in logarithmic growth phase were treated with recombinant human TRAIL (Bender MedSystems, Austria) at 0, 12.5, 25, 50 and $100 \mathrm{ng} / \mathrm{ml}$ for $24 \mathrm{~h}$. Detached and attached cells were collected. The fluorescence of the stained cells was analyzed with FACScan (BD Biosciences, Canada). The apoptotic cells consisted of Annexin $\mathrm{V}(+) / \mathrm{PI}(-)$ and Annexin V(+)/PI(+) cells. Results were repeated twice.

Telomerase activity and telomere length detection. Telomerase activity was measured by telomeric repeat amplification protocol (TRAP) as described previously (17). Mean telomere length was measured using solution hybridizationbased method named as telomere amount and length assay (TALA) as described previously $(18,19)$. Results were all repeated twice.

Western blot analysis. Cells in culture were harvested and lysed in T-PER Tissue Protein Extraction. The lysed cells were centrifuged at $18,000 \mathrm{x}$ g for $15 \mathrm{~min}$. Protein concentrations of the cell extracts were measured by Lowry's method. Proteins $(50 \mu \mathrm{g})$ were separated by PAGE under reducing conditions, transferred onto PVDF membranes (Pierce, USA) and detected with enhanced chemiluminescence (ECL) reagents (Pierce). The following antibodies were used: caspase-8 (Cell Signaling, USA), caspase-9, caspase-3, Bcl-2, Bax and Actin (Santa Cruz, USA). Secondary horseradish peroxidase-conjugated goat anti-mouse, goat anti-rat and goat anti-rabbit antibodies were used.

Data analysis. Band intensions of RT-PCR experiments were evaluated densitometrically using Quantity One analysis software (Bio-Rad). For statistical analysis, data were subjected to one-way or two-way ANOVA using SPSS 11.5 for Windows (SPSS, USA). Differences between experimental groups were determined by $F$ test. Differences were considered statistically significant at $\mathrm{P}<0.05$.

\section{Results}

Identification of recombinant plasmid and interference sequence. PCR amplified product of pSilencer 3.1-HI neoshTERT was $327 \mathrm{bp}$. After restriction with enzymes, the product with single enzyme resection was $4288 \mathrm{bp}$ and that with paired enzyme resection was 4224 bp and 64 bp. Combined with the result of DNA sequencing, it revealed that the sequence of inserted shTERT was correct (Fig. 1A). Huh7 and Hep3B cells were transfected with recombinant and control plasmids. The cell clones were selected and genomic DNA was extracted. DNA of the recombinant plasmids served as positive control and DNA of untransfection cells as negative control. The results of PCR amplification are shown (Fig. 1B). Amplified products were found in $6 / 8$ clones of Huh7 cells and in 6/6 clones of Hep3B cells and they were preserved for next experiments.

hTERT RNAi inhibits hTERT mRNA expression in transfected $H C C$ cells. Expression of hTERT mRNA was determined 
A

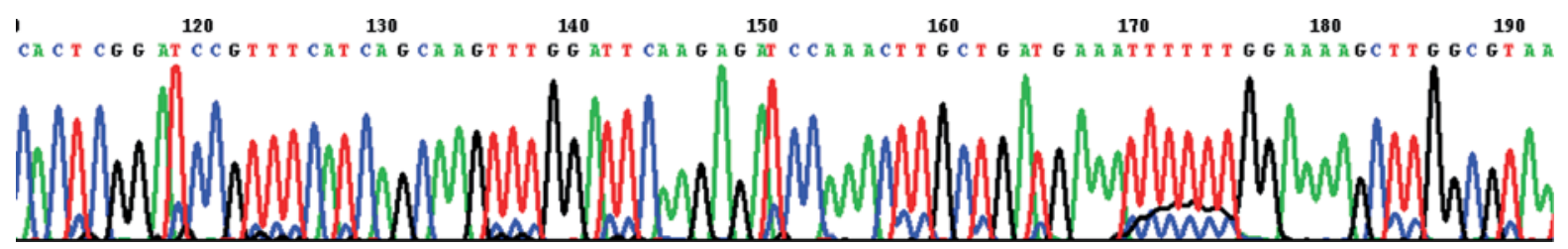

B

transfected cells

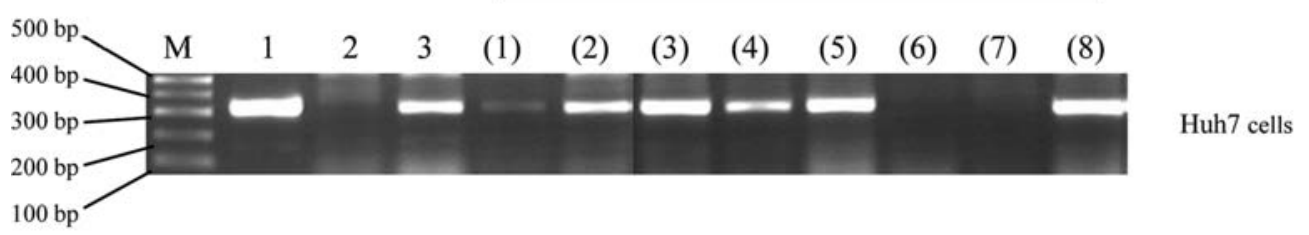

transfected cells

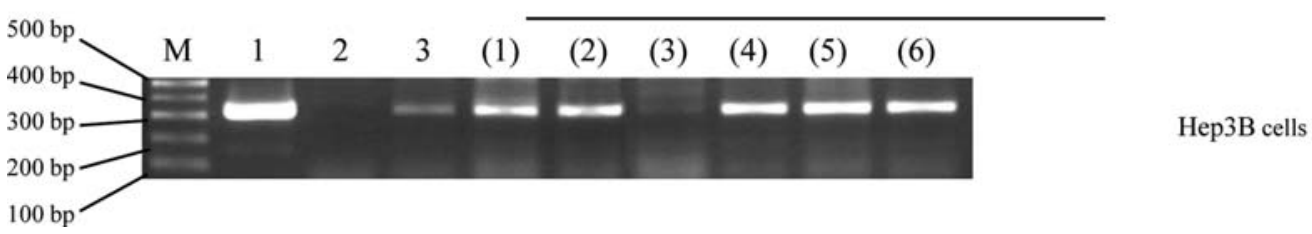

Figure 1. Identification of recombinant plasmid and interference sequence. (A) Sequencing of recombinant plasmid. There was a correct hTERT interference sequence in the recombinant plasmid. hTERT interference sequence was $64 \mathrm{bp}$, which is arranged from 117 to $180 \mathrm{bp}$. (B) Identification of interference sequence in transfected Huh7 cells and Hep3B cells. PCR amplified products of interference sequence were found in 6/8 clones of Huh7 cells and in 6/6 clones of Hep3B cells. Lane 1, recombinant plasmid; lane 2, untransfected cells; lane 3, control cells; lane M, PCR marker; lanes (1-8), clones of Huh7 cells; lanes (1-6), clones of Hep3B cells.

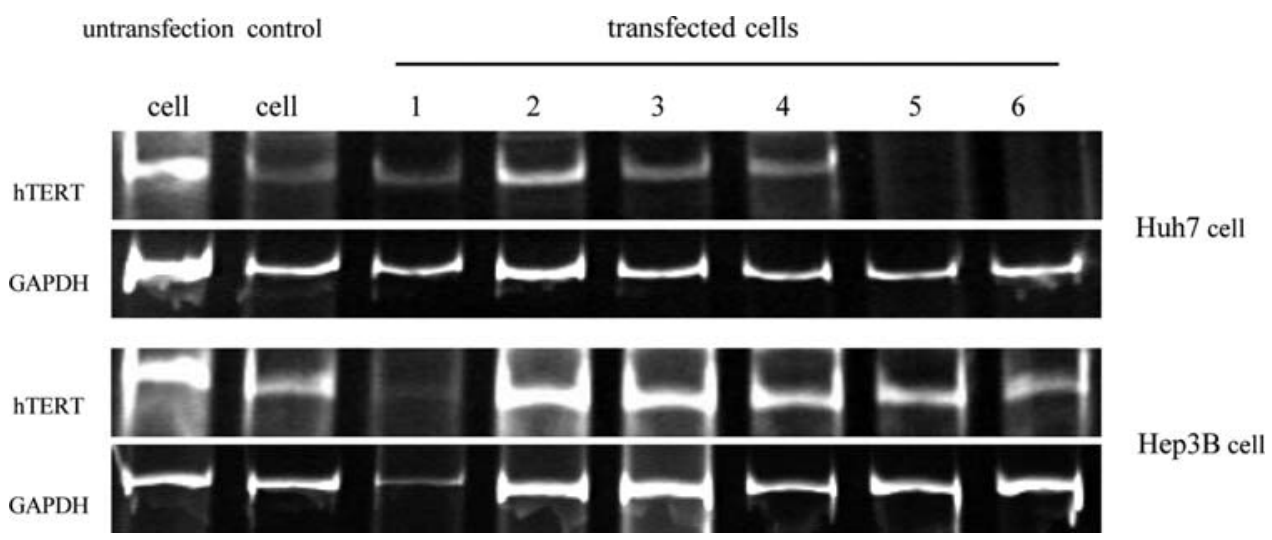

Figure 2. hTERT mRNA expression in untransfected, control and transfected cells. The interference rate of hTERT was significantly higher in the 5th and 6th transfected clones of Huh7 cells and 1st clone of Hep3B cells. Lanes 1-6, transfected cell clones.

with RT-PCR method and the results are shown in Fig. 2. Compared with untransfection cells, the interference rate of hTERT in control Huh7 cells was $9.979 \%$, in transfected Huh7 cells (clones 1-6) were 10.49, 7.622, 8.707, 0.3143, 100 and $100 \%$ respectively; interference rate of hTERT in control Hep3B cells was $24.22 \%$, in ransfected Hep3B cells (clones 1 to 6 ) were $30.97,32.61,40.02,24.17,36.18$ and $63.28 \%$, respectively. Statistical analysis revealed that the interference rate of hTERT was significantly higher in the 5th and 6th transfected clones of Huh7 cells than 1st to 4th clones $(\mathrm{P}<0.05)$. The interference rate of hTERT was significantly higher in the transfected 1 st clone of Hep3B cells than in the 2 nd to 6 th clones $(\mathrm{P}<0.05)$. Therefore, the 6th clone of Huh7 and 1st clone of Hep3B were used to investigate TRAIL-induced apoptosis and its corresponding mechanisms.

hTERT RNAi sensitizes resistant HCC cells for TRAIL-induced apoptosis. We examined effect of hTERT RNAi on TRAILinduced apoptosis in human HCC cell lines Huh-7 and Hep3B at different concentrations. Our results showed that TRAIL was unable to induce apoptosis effectively in the two types of cells even at the concentration up to $100 \mathrm{ng} / \mathrm{ml}(<15 \%)$. However, hTERT RNAi reversed the resistance to TRAIL in two cell lines and induced significant apoptosis in a dosedependent manner, which was far higher than that of the 

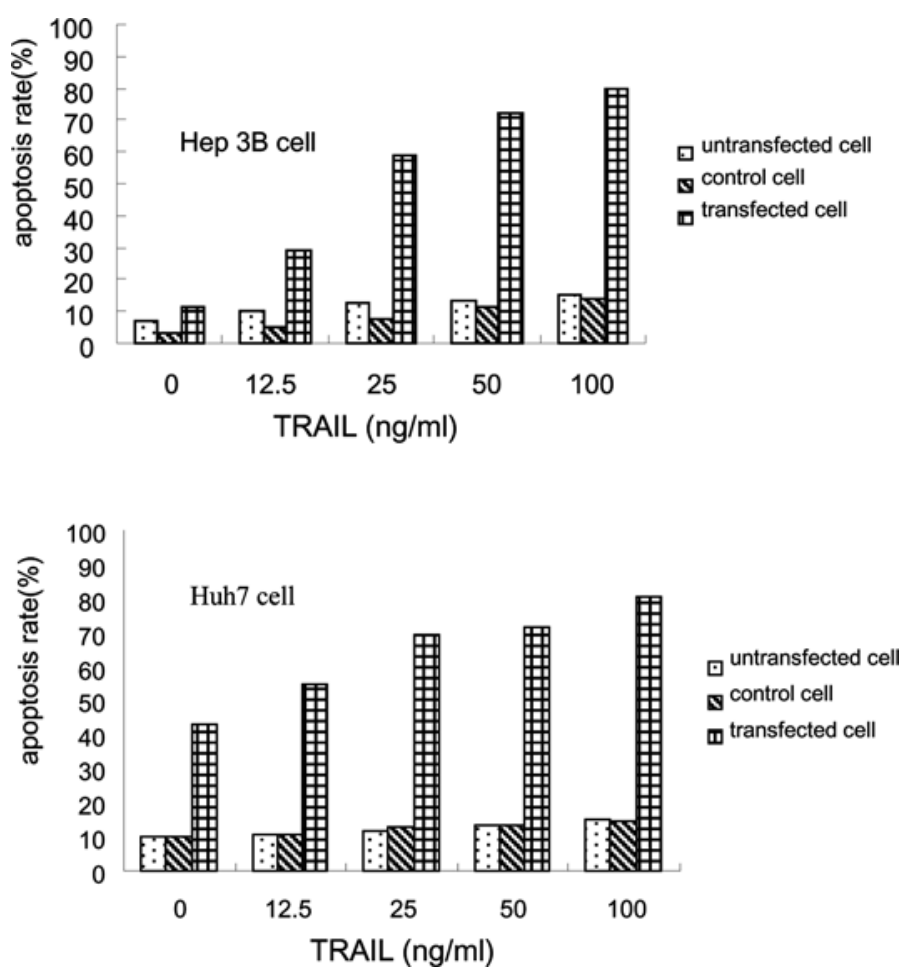

Figure 3. Effects of hTERT RNAi on TRAIL-induced apoptosis. TRAIL was unable to induce apoptosis effectively in the two types of cells even at the concentration up to $100 \mathrm{ng} / \mathrm{ml}(<15 \%)$. However, hTERT RNAi reversed the resistance to TRAIL in two cell lines and induced significant apoptosis in a dose-dependent manner.

untransfected and control cells $(\mathrm{P}<0.05)$. However, there was no obvious effect on control and untranfected cells (Fig. 3).

Western blot analysis showed that cleavage of the proenzymes into the active fragments of caspase- $8,-9$ and -3 was only found in transfected cells treated with TRAIL but not in untransfected and control cells (Fig. 4). This suggests that the mitochondrial type II apoptosis pathway contributes to the hTERT RNAi-mediated sensitization to TRAIL-induced apoptosis.

hTERT RNAi up-regulates the expression of procaspase-8, -9, and $\mathrm{Bcl}-2$, and down-regulates the expression of Bax in resistant HCC cells. Expression of apoptosis-associated proteins were detected with Western blot analysis (Fig. 5). hTERT RNAi obviously increased the expression of procaspase- $8,-9$, and $\mathrm{Bcl}-2(\mathrm{P}<0.05)$ and decreased the expression of Bax in resistance HCC cells $(\mathrm{P}<0.05)$. However, expression of procaspase- 3 was not notably different compared with untransfected and control cells $(\mathrm{P}>0.05)$.

hTERT RNAi inhibits telomerase activity in resistant HCC cells. Telomerase activities were detected with TRAP method (Fig. 6A). Compared with untransfected cells and control cells, transfected cells showed obviously decreased telomerase activities. Statistical analysis indicated that hTERT RNAi significantly decreased telomerase activities of transfected cells $(\mathrm{P}<0.05)$, but there were no obvious differences between untransfected and control cells $(\mathrm{P}>0.05)$.

hTERT RNAi significantly decreased telomere length in resistant HCC cells. Telomere length was detected with
TALA method (Fig. 6B). In Huh7 cells, compared with untransfected cells, telomere length increased $2.057 \%$ in control cells, but decreased $13.29 \%$ in transfected cells. In Hep3B cells, contrast to untransfected cells, telomere length increased $1.646 \%$ in control cells. However, telomere length could not be detected in transfected cells for its telomere disappeared. Statistical analysis revealed that hTERT RNAi significantly decreased telomere length of transfected cells $(\mathrm{P}<0.05)$, but there were no obvious differences between untransfected and control cells $(\mathrm{P}>0.05)$.

\section{Discussion}

Although TRAIL is a potent inducer of apoptosis in cancer cells, there are still several TRAIL-resistant cancer cells. Many successful approaches have been deviced to overcome this resistance, such as the combination of TRAIL with reagents such as DNA damaging agents $(20,21)$, ionizing radiation (22), or virus expressing wild-type p53 (23). In this study, we tested the effect of hTERT RNAi on the TRAIL-induced apoptosis in TRAIL-resistant HCC cell lines. We found that hTERT RNAi can sensitize TRAIL-resistant HCC cells to TRAILinduced apoptosis, suggesting that hTERT may be a suitable target molecule for drug-resistant HCCs.

Although TRAIL has been reported to induce apoptosis in a variety of tumor cell types including HCC cell lines (24), the molecular mechanisms that regulate sensitivity versus resistance of HCC cells to TRAIL-induced apoptosis remain poorly defined. Two main signaling pathways have been delineated to initiate the apoptosis in mammalian cells, the extrinsic and intrinsic pathways (25). The extrinsic pathway 
A

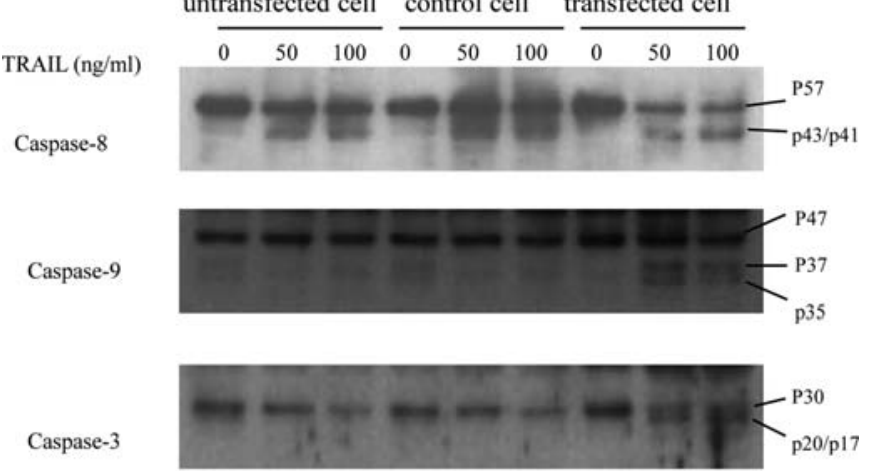

Actin

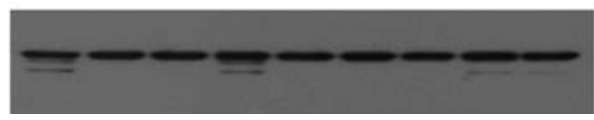

B

TRAIL (ng/ml)

Caspase-8

untransfected cell control cell transfected cell

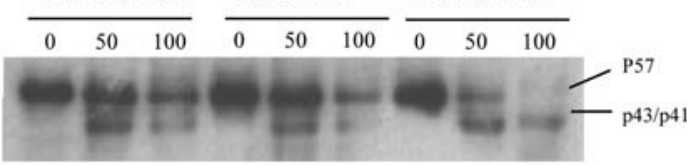

Caspase-9

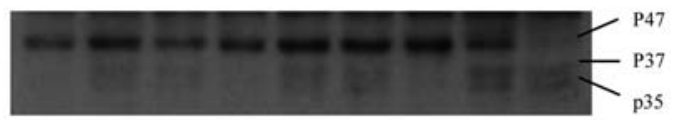

Caspase- 3

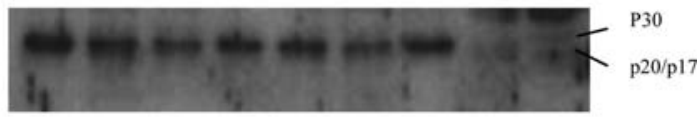

Actin

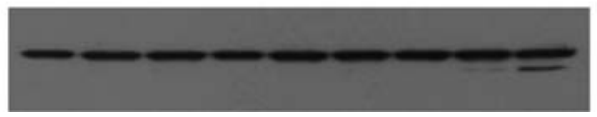

Figure 4. The effects of TERT RNAi on the cleavage of the proenzymes into the active fragments of caspase- $8,-9$ and -3 . (A) Western blot analysis showed that the activation of caspases and cleavage of their substrates was only found in transfected Huh7 cells treated with TRAIL. (B) Western blot analysis showed that the activation of caspases and cleavage of their substrates was only found in transfected Hep3B cells treated with TRAIL.

can be initiated by members of the TNF superfamily, which later leads to activation of caspase-8 (26). TRAIL triggers apoptosis through interaction with their death receptors DR4/DR5 and subsequent recruitment of intra-cellular adaptor Fas-associated death domain (FADD) (27). FADD in turn recruits caspase- 8 through interaction of their death effector domains (DED), leading to the assembly of deathinducing signaling complex (DISC) (28).

In the DISC, caspase- 8 is cleaved and activated through autoproteolysis (29) and subsequently cleaves caspase-3 (30) and Bcl-2 inhibitory BH3-domainprotein (Bid) (31). The truncated Bid interacts with Bax and Bak and induces mitochondrial release of cytochrome c into the cytosol (32) in which caspase-9 is activated and cleaves caspase-3 (33). Caspase-3 in turn cleaves its substrates such as DNA fragmentation factor 45 (DFF45), leading to apoptosis (34). Accordingly, our results showed that the cleavage of proenzymes into the active fragments of caspase- $8,-9$ and -3

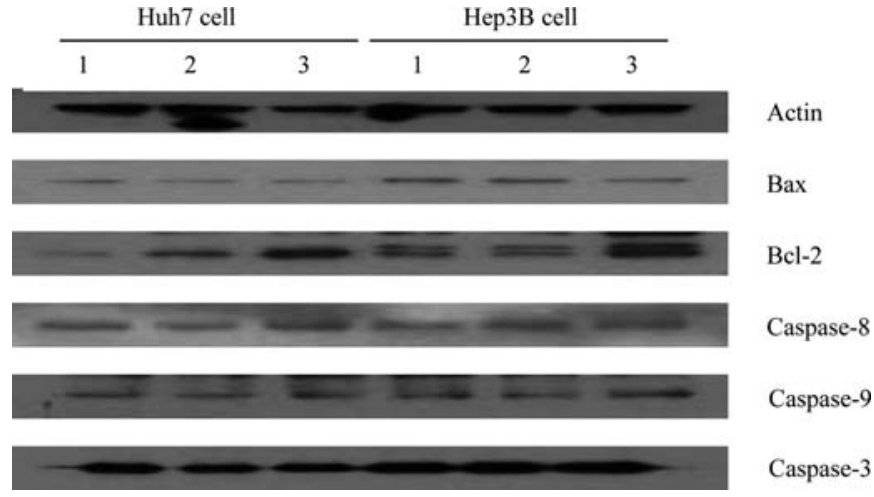

Figure 5. Effect of hTERT RNAi on expression of apoptosis-associated proteins. Western blot analysis showed that hTERT RNAi obviously increased the expression of procaspase- $8,-9$, and $\mathrm{Bcl}-2$ and decreased the expression of Bax in TRAIL-resistance HCC cells. However, expression of procaspase-3 was not significantly different from untransfected and control cells. Lane 1, untransfected cells; lane 2, control cells; lane 3, transfected cells.
A

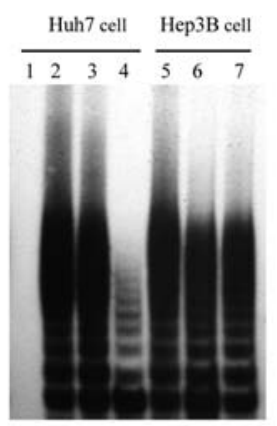

B

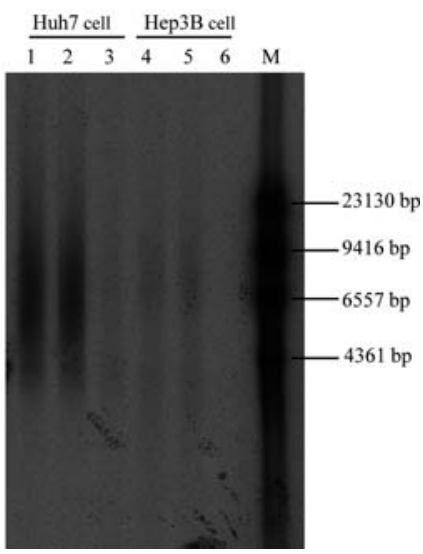

Figure 6. Effects of hTERT RNAi on telomerase activity and telomere length in Huh7 cells and Hep3B cells. (A) hTERT RNAi inhibits telomerase activity in TRAIL-resistant HCC cells. Lane 1, RNase A treatment; lanes 2 and 5, untransfected cells; lanes 3 and 6, control cell; lanes 4 and 7, transfected cells. (B) hTERT RNAi decreased telomere length in TRAIL-resistant HCC cells. Lanes 1 and 4, untransfected cells; lanes 2 and 5, control cells; lanes 3 and 6 , transfected cells; M, $\lambda$ DNA/HindIII marker.

was only found in transfected cells treated with TRAIL, but not in untransfected and control cells, and thus enhancing procaspase- 8 , and -9 expression. These results indicate the importance of intrinsic mitochondria pathway in hTERT RNAi mediated TRAIL-induced apoptotic cell death. However, procaspase-3 did not correspondingly increase. The mechanism is unknown and may be involved in augmenting cell apoptosis and accentuation of procaspase-3 cleavage in HCC cells with hTERT RNAi.

Bcl-2 family proteins play important roles in regulating mitochondrial permeabilization and activation of caspases, and are classified as two groups in this family, anti-apoptotic members (e.g. Bcl-2 and Bcl-xL) and pro-apoptotic members (e.g. Bid and Bcl-xS) (35). The Bcl-2 family of proteins regulates apoptosis and it has been demonstrated that the gene products of $\mathrm{Bcl}-2$ and Bax play important roles in apoptotic cell death (36). In this study, an increase in the 
level of proapoptotic protein Bax with a decrease in level of anti-apoptotic protein Bcl-2 was observed in hTERT RNAi TRAIL-resistant HCC cells, suggesting that Bcl-2 family proteins may be involved in hTERT RNAi mediated TRAILinduced apoptotic cell death.

Telomerase activation is one of the critical steps in malignant transformation. It contributes to installing an immortal cell phenotype by preventing apoptosis, and may play a role in cellular resistance to anticancer drugs (37-39). Although telomerase is a complex composed of hTR, hTERT and TEP1, telomerase activity is mainly transcriptionally controlled by the hTERT promoter (40). It has been shown that telomerase is strongly activated in the majority of HCCs and the degree of telomerase activation correlates with histologic dedifferentiation of the tumors (41), providing a precondition for effective telomerase-dependent therapy. Moreover, the sensitivity of tumor cells to chemotherapy and radiotherapy significantly increase after telomere erosion and telomerase activity drop (42). In this study, we found that hTERT RNAi resulted in inhibition of telomerase, telomere erosion, and enhanced the cytotoxicity of TRAIL in TRAILresistant HCC cells. These results indicat that hTERT RNAi mediated TRAIL-induced apoptosis may be related to inhibition of telomerase and erosion of telomere.

In conclusion, our results indicate that hTERT RNAi sensitizes TRAIL-resistant HCC cells to TRAIL-induced apoptosis. hTERT RNAi-mediated sensitization to TRAILinduced apoptosis is accompanied up-regulation of procaspase -8 , and -9 , inhibition of telomerase activity and erosion of telomere length, suggesting that hTERT RNAi overcame the resistance of the HCC cells against TRAIL, at least in part, via intrinsic pathway and telomerase-dependent pathway.

\section{Acknowledgements}

This work was financially supported by the Scientific Research Foundation of Chinese PLA, during the 10th-Five-Year Plan Period, No. 01MA172.

\section{References}

1. Smyth MJ, Takeda K, Hayakawa Y, Peschon JJ, van den Brink MR and Yagita H: Nature's TRAIL - On a path to cancer immunotherapy. Immunity 18: 1-6, 2003.

2. Zhang L and Fang B: Mechanisms of resistance to TRAILinduced apoptosis in cancer. Cancer Gene Ther 12: 228-237, 2005.

3. Feng J, Funk WD, Wang SS, et al: The RNA component of human telomerase. Science 269: 1236-1241, 1995.

4. Nakamura TM, Morin GB, Chapman KB, Weinrich SL, Andrews WH, Lingner J, Harley CB and Cech TR: Telomerase catalytic subunit homologs from fission yeast and human. Science 277: 955-959, 1997.

5. Harrington L, McPhail T, Mar V, Zhou W, Oulton R, Bass MB, Arruda I and Robinson MO: A mammalian telomeraseassociated protein. Science 275: 973-977, 1997.

6. Counter CM, Meyerson M, Eaton EN, Ellisen LW, Caddle SD, Haber DA and Weinberg RA: Telomerase activity is restored in human cells by ectopic expression of hTERT (hEST2), the catalytic subunit of telomerase. Oncogene 16: 1217-1222, 1998.

7. Meyerson M, Counter CM, Eaton EN, Ellisen LW, Steiner P, Caddle SD, Ziaugra L, Beijersbergen RL, Davidoff MJ, Liu Q, Bacchetti S, Haber DA and Weinberg RA: hEST2, the putative human telomerase catalytic subunit gene, is up-regulated in tumor cells and during immortalization. Cell 90: 785-795, 1997.
8. Terrin L, Rampazzo E, Pucciarelli S, Agostini M, Bertorelle R, Esposito G, DelBianco P, Nitti D and De Rossi A: Relationship between tumor and plasma levels of hTERT mRNA in patients with colorectal cancer: implications for monitoring of neoplastic disease. Clin Cancer Res 14: 7444-7451, 2008.

9. Bièche I, Noguès C, Paradis V, Olivi M, Bedossa P, Lidereau R and Vidaud M: Quantitation of hTERT gene expression in sporadic breast tumors with a real-time reverse transcription- polymerase chain reaction assay. Clin Cancer Res 6: 452-459, 2000.

10. Ramakrishnan S, Eppenberger U, Mueller H, Shinkai Y and Narayanan R: Expression profile of the putative catalytic subunit of the telomerase gene. Cancer Res 58: 622-625, 1998.

11. Takakura M, Kyo S, Kanaya T, Tanaka M and Inoue $M$ : Expression of human telomerase subunits and correlation with telomerase activity in cervical cancer. Cancer Res 58: 1558-1561, 1998.

12. Toshikuni N, Nouso K, Higashi T, Nakatsukasa H, Onishi T, Kaneyoshi T, Kobayashi Y, Kariyama K, Yamamoto K and Tsuji T: Expression of telomerase-associated protein 1 and telomerase reverse transcriptase in hepatocellular carcinoma. $\mathrm{Br}$ J Cancer 82: 833-837, 2000.

13. Park YM, Choi JY, Byun BH, Cho CH, Kim HS and Kim BS: Telomerase is strongly activated in hepatocellular carcinoma but not in chronic hepatitis and cirrhosis. Exp Mol Med 30: 35-40, 1998.

14. Kawakami Y, Kitamoto M, Nakanishi T, Yasui W, Tahara E, Nakayama J, Ishikawa F, Tahara H, Ide T and Kajiyama G: Immunohistochemical detection of human telomerase reverse transcriptase in human liver tissues. Oncogene 19: 3888-3893, 2000.

15. Masutomi K, Yu EY, Khurts S, Ben-Porath I, Currier JL, Metz GB, Brooks MW, Kaneko S, Murakami S, DeCaprio JA, Weinberg RA, Stewart SA and Hahn WC: Telomerase maintains telomere structure in normal human cells. Cell 114: 241-253, 2003.

16. Lin SY and Elledge SJ: Multiple tumor suppressor pathways negatively regulate telomerase. Cell 113: 881-889, 2003.

17. Kim NW, Piatyszek MA, Prowse KR, Harley CB, West MD, Ho PL, Coviello GM, Wright WE, Weinrich SL and Shay JW: Specific association of human telomerase activity with immortal cells and cancer. Science 266: 2011-2015, 1994.

18. Gan Y, Engelke KJ, Brown CA and Au JL: Telomere amount and length assay. Pharm Res 18: 1655-1659, 2001.

19. Mo Y, Gan Y, Song S, Johnston J, Xiao X, Wientjes MG and Au JL: Simultaneous targeting of telomeres and telomerase as a cancer therapeutic approach. Cancer Res 63: 579-585, 2003.

20. Nagane M, Pan G, Weddle JJ, Dixit VM, Cavenee WK and Huang HJ: Increased death receptor 5 expression by chemotherapeutic agents in human gliomas causes synergistic cytotoxicity with tumor necrosis factor-related apoptosis-inducing ligand in vitro and in vivo. Cancer Res 60: 847-853, 2000.

21. Kim K, Fisher MJ, Xu SQ and El-Deiry WS: Molecular determinants of response to TRAIL in killing of normal and cancer cells. Clin Cancer Res 6: 335-346, 2000.

22. Chinnaiyan AM, Prasad U, Shankar S, Hamstra DA, Shanaiah M, Chenevert TL, Ross BD and Rehemtulla A: Combined effect of tumor necrosis factor-related apoptosis-inducing ligand and ionizing radiation in breast cancer therapy. Proc Natl Acad Sci USA 97: 1754-1759, 2000.

23. Kim K, Takimoto R, Dicker DT, Chen Y, Gazitt Y and ElDeiry WS: Enhanced TRAIL sensitivity by p53 overexpression in human cancer but not normal cell lines. Int J Oncol 18: 241-247, 2001

24. Yamanaka T, Shiraki K, Sugimoto K, Ito T, Fujikawa K, Ito M, Takase K, Moriyama M, Nakano T and Suzuki A: Chemotherapeutic agents augment TRAIL-induced apoptosis in human hepatocellular carcinoma cell lines. Hepatology 32: 482-490, 2000.

25. Ashkenazi A: Targeting death and decoy receptors of the tumour-necrosis factor superfamily. Nat Rev Cancer 2: 420-430, 2002.

26. Takeda K, Stagg J, Yagita H, Okumura K and Smyth MJ: Targeting death-inducing receptors in cancer therapy. Oncogene 26: 3745-3757, 2007.

27. Wang S and El-Deiry WS: TRAIL and apoptosis induction by TNF-family death receptors. Oncogene 22: 8628-8633, 2003.

28. Kischkel FC, Hellbardt S, Behrmann I, Germer M, Pawlita M, Krammer PH and Peter ME: Cytotoxicity-dependent APO-1 (Fas/CD95)-associated proteins form a death-inducing signaling complex (DISC) with the receptor. EMBO J 14: 5579-5588, 1995. 
29. Muzio M, Stockwell BR, Stennicke HR, Salvesen GS and Dixit VM: An induced proximity model for caspase-8 activation. J Biol Chem 273: 2926-2930, 1998.

30. Thornberry NA, Rano TA, Peterson EP, Rasper DM, Timkey T, Garcia-Calvo M, Houtzager VM, Nordstrom PA, Roy S, Vaillancourt JP, Chapman KT and Nicholson DW: A combinatorial approach defines specificities of members of the caspase family and granzyme B. Functional relationships established for key mediators of apoptosis. J Biol Chem 272: 17907-17911, 1997

31. Li H, Zhu H, Xu CJ and Yuan J: Cleavage of BID by caspase 8 mediates the mitochondrial damage in the Fas pathway of apoptosis. Cell 94: 491-501, 1998 .

32. Luo X, Budihardjo I, Zou H, Slaughter C and Wang X: Bid, a $\mathrm{Bcl} 2$ interacting protein, mediates cytochrome c release from mitochondria in response to activation of cell surface death receptors. Cell 94: 481-490, 1998.

33. Li P, Nijhawan D, Budihardjo I, Srinivasula SM, Ahmad M, Alnemri ES and Wang X: Cytochrome $\mathrm{c}$ and dATP-dependent formation of Apaf-1/caspase-9 complex initiates an apoptotic protease cascade. Cell 91: 479-489, 1997.

34. Liu X, Zou H, Slaughter C and Wang X: DFF, a heterodimeric protein that functions downstream of caspase- 3 to trigger DNA fragmentation during apoptosis. Cell 89: 175-184, 1997.

35. Chan SL and Yu VC: Proteins of the bcl-2 family in apoptosis signalling: from mechanistic insights to therapeutic opportunities. Clin Exp Pharmacol Physiol 31: 119-128, 2004.

36. Jacobson MD and Raff MC: Programmed cell death and Bcl-2 protection in very low oxygen. Nature 374: 814-816, 1995.
37. Kondo Y, Kondo S, Tanaka Y, Haqqi T, Barna BP and Cowell JK: Inhibition of telomerase increases the susceptibility of human malignant glioblastoma cells to cisplatin-induced apoptosis. Oncogene 16: 2243-2248, 1998.

38. Fu W, Begley JG, Killen MW and Mattson MP: Anti-apoptotic role of telomerase in pheochromocytoma cells. J Biol Chem 274: 7264-7271, 1999.

39. Kushner DM, Paranjape JM, Bandyopadhyay B, Cramer H, Leaman DW, Kennedy AW, Silverman RH and Cowell JK: 2-5A antisense directed against telomerase RNA produces apoptosis in ovarian cancer cells. Gynecol Oncol 76: 183-192, 2000.

40. Nakayama J, Tahara H, Tahara E, Saito M, Ito K, Nakamura H, Nakanishi T, Tahara E, Ide T and Ishikawa F: Telomerase activation by hTRT in human normal fibroblasts and hepatocellular carcinomas. Nat Genet 18: 65-68, 1998.

41. Kojima H, Yokosuka O, Imazeki F, Saisho H and Omata M: Telomerase activity and telomere length in hepatocellular carcinoma and chronic liver disease. Gastroenterology 112: 493-500, 1997.

42. González-Suárez E, Goytisolo FA, Flores JM and Blasco MA: Telomere dysfunction results in enhanced organismal sensitivity to the alkylating agent $\mathrm{N}$-methyl-N-nitrosourea. Cancer Res 63: 7047-7050, 2003 . 